\title{
EL FANTASMA \\ DE SEBASTIÁN \\ LERDO DE TEJADA
}

Alonso Lujambio*

RESUMEN: Para la reedición del libro Memorias de Sebastián Lerdo de Tejada, el autor presenta una extensa noticia de la vida del ex-presidente mexicano, su exilio en Nueva York, las conversaciones que allí mantuvo con Adolfo Rogaciano Carrillo, y el papel que este periodista tuvo en la publicación de dichas Memorias, todo en el contexto político mexicano de la época.

\section{rose}

ABSTRACT: In honor of the reedition of Sebastián Lerdo de Tejada's Memoirs, the author presents an extensive view of the former Mexican president's life, his exile in New York where he had conversations with the journalist, Adolfo Rogaciano Carrillo, and finally, the role that this journalist played in the publication of his Memoirs and in the Mexican political environment of that time.

PALABRAS ClaVE: Sebastián Lerdo de Tejada, Memorias, Adolfo Rogaciano Carrillo, Porfirio Díaz, Revolución mexicana.

KEY WORDS: Sebastián Lerdo de Tejada, Memoirs, Adolfo Rogaciano Carrillo, Porfirio Díaz, Mexican Revolution.

RECEPCIÓN: 25 de agosto de 2011. APROBACIÓN: 29 de agosto de 2011.

* Secretario de Educación Pública. 
CITAM Derechos Reservados.

La reproducción total o parcial de este artículo se podrá hacer si el ITAM otorga la autorización previamente por escrito. 


\section{EL FANTASMA \\ DE SEBASTIÁN \\ LERDO DE TEJADA*}

A Sebastián Lujambio Toca

\section{Sebastián en Nueva York}

1 domingo 21 de abril de 1889 , en
la residencia Lenox House de la ciudad de Nueva York, murió el ex-presidente mexicano Sebastián Lerdo de Tejada, a los 66 años de edad y tras doce de vida en el exilio. Lerdo de Tejada había sido presidente de México entre 1872 y 1876, año con el que termina una etapa histórica, la llamada República restaurada, e inicia otra, la del largo dominio de Porfirio Díaz, que se prolongará por más de treinta años, hasta 1910, en el arranque de la Revolución mexicana. Díaz no renunciará sino hasta mayo de 1911, y partirá hacia el exilio en Europa. En 1876, la revuelta exitosa de Tuxtepec es comandada por Porfirio Díaz, lo que explica el derrocamiento de Lerdo de Tejada y el hecho de que el ex-presidente mexicano pase la última etapa de su vida en el exilio neoyorkino.

La vida política de Sebastián Lerdo de Tejada había sido civil, no militar; se dio desde el principio en puestos institucionales de alto rango y fue verdaderamente meteórica. Lerdo de Tejada nació en 1823 en Jalapa, la capital del estado de Veracruz. Entre 1836 y 1841, esto es, de los 13 a los 18 años, Sebastián estudia teología en el Seminario Pala-

* Este texto se publicará próximamente como estudio introductorio de la reedición del libro Memorias de Sebastián Lerdo de Tejada, a cargo del Instituto Nacional de Estudios Históricos de las Revoluciones de México (INEHRM). 
foxiano de la ciudad de Puebla y dirige sus pasos hacia la vida religiosa. Sin embargo, en 1841 se muda a la ciudad de México y cambia su decisión: estudiará leyes en el prestigiado Colegio de San Ildefonso. En 1849, cuando tiene 25 años, es profesor del Colegio y muy joven, a los 29, Sebastián Lerdo de Tejada es nombrado Rector del Colegio de San Ildefonso. Es el momento de pleno conflicto entre el presidente Mariano Arista y el Congreso. Era 1852. Arista acabará renunciando a la presidencia ante la imposibilidad de llegar a acuerdos con el Congreso y ello dará pauta a la última dictadura de Santa Anna, que se inicia en abril de 1853 y termina con la Revolución de Ayutla, comandada por los liberales, en agosto de 1855. Así, el nuevo dominio de los liberales -Lerdo de Tejada uno de ellos, junto con su destacado hermano mayor, Miguel- llevará a la promulgación de la Constitución de 1857.

Sebastián Lerdo de Tejada será a los 34 años ministro de Relaciones Exteriores del presidente Ignacio Comonfort, en los meses previos a la entrada en vigor de la Constitución de 1857; después será diputado al Congreso, en el tránsito del fin de la Guerra de Tres Años entre liberales y conservadores (1858-1860) al inicio de la intervención francesa (1862-1867); posteriormente, fue ministro de Relaciones Exteriores del presidente Benito Juárez durante los largos años de la República itinerante, durante el llamado Segundo imperio y, a partir del triunfo de los liberales sobre Maximiliano de Habsburgo, es decir, con la Restauración de la República a mediados de 1867, será electo presidente de la Suprema Corte de Justicia de la Nación. Tiene entonces 44 años. En julio de 1872, al morir Juárez, Lerdo de Tejada se convierte en presidente de la República, pues la Constitución de 1857 ordenaba que el sustituto, a falta absoluta del titular del Poder Ejecutivo, fuese precisamente quien presidiera la Corte. Pocos meses después, en octubre de 1872, es electo presidente de la República para el período 1872-1876, con el apoyo del juarismo sobreviviente y, por supuesto, del llamado lerdismo. En ese momento tiene 49 años.

En 1876, Lerdo de Tejada intenta reelegirse, al tiempo que enfrenta la revolución tuxtepecana que abandera Porfirio Díaz y que impulsa, por la vía armada, el principio de la no reelección presidencial. Años después, Díaz traicionaría su propia bandera y se reelegirá, ya dictador, 
hasta la ancianidad. Enfrentado a Porfirio Díaz, Sebastián Lerdo de Tejada perdió en 1876, en parte porque el juarismo se dividió. Destacados militares juaristas apoyan a Lerdo de Tejada (Ignacio Mejía, Mariano Escobedo), y destacados políticos juaristas apoyan a Díaz (Matías Romero, Ignacio Mariscal). La base de apoyo de Lerdo de Tejada también se dividió: José María Iglesias, nuevo presidente de la Suprema Corte de Justicia, reclama la presidencia ante el vacío de legitimidad de las elecciones presidenciales de 1876, en las que chocan Lerdo de Tejada y Díaz. Total: el lerdismo ya no cuenta con el apoyo completo del juarismo, por demás disminuido, y el iglesismo apuesta por separado. Los tuxtepecanos de 1876, comandados por Porfirio Díaz, ganarán la batalla porque sumaron adeptos y porque se fragmentó el bando adversario. Díaz se hacía, así, del poder. Derrotado, Lerdo de Tejada sale del país a finales de 1876 por el puerto de Acapulco hacia Panamá, para de ahí seguir hacia la ciudad de Nueva York. Tiene entonces 53 años.

En definitiva, con el exilio de Lerdo de Tejada concluía la etapa conocida como la República restaurada (1867-1876), que va del triunfo de la República contra el Segundo imperio en 1867 al golpe de Tuxtepec en 1876. Son presidentes, en esos nueve años, Benito Juárez y Sebastián Lerdo de Tejada. Éste fue, en la historia del siglo XIX mexicano, el gran derrotado por el dictador Porfirio Díaz. Lerdo de Tejada quedó históricamente en medio de dos gigantes políticos, ambos oaxaqueños, Juárez y Díaz, los presidentes mexicanos que más han permanecido en el poder. Poco después, una intentona lerdista en el norte del país fracasará rotundamente, al mando de Mariano Escobedo. Muy pronto Lerdo de Tejada comprende el carácter definitivo de su derrota y decide quedarse en la urbe de hierro hasta su muerte en 1889. Lerdo de Tejada nunca quiso, con su regreso a México, legitimar el régimen porfirista. Rechazó en Nueva York la visita -bastante cínica-de Díaz. Murió solo. Era soltero. Pasó los últimos años de su vida en la lectura, en la atención jurídica de algún caso, en largas caminatas por las calles de la ciudad. ${ }^{1}$

${ }^{1}$ Frank A. Knapp, The life of Sebastián Lerdo de Tejada, 1823-1889. A study of influence and obscurity, 1951, Austin, The University of Texas Press. La Universidad Veracruzana publicó en 1962 la traducción de Francisco González Aramburo. La veracruzana es la única 
ALONSO LUJAMBIO

Sebastián Lerdo de Tejada pasa a la historia de México por muchas razones, pero son especialmente destacables dos, muy propias de su talento como ingeniero político-constitucional de altos vuelos. En primer lugar, impulsó que el Congreso mexicano introdujera en la Constitución las Leyes de Reforma para consolidar la victoria, en el ordenamiento jurídico, del liberalismo, pero también logró que el Congreso enmendara la Constitución para el reequilibrio de poderes y restableciera el Senado de la República, desaparecido por el unicameralismo "asambleístico" de la Constitución de 1857. Lerdo de Tejada le dio poder al Estado para impulsar la agenda liberal y ajustó los pesos y contrapesos en las instituciones del Estado. No fue poca cosa. Por lo demás, con la gran reforma constitucional de 1874, Lerdo de Tejada enmendaba un gran error político, que lo distanció de Juárez en 1867; equivocadamente, Lerdo de Tejada impulsó la idea, al concluir el Imperio de Maximiliano, de que, para la vuelta al orden constitucional previsto por la Constitución de 1857, era necesario, después de la guerra, ir a elecciones democráticas, pero antes debía darse una especie de refundación del pacto estatal, apelando directamente al pueblo, para reformar a profundidad el orden constitucional. Se argumenta que la Convocatoria del 24 de agosto de 1867 a un plebiscito para reformar la Constitución no sigue literalmente el procedimiento de reforma establecido en la propia Constitución. Por su lado, Lerdo de Tejada alega que el plebiscito sí tiene fundamento constitucional, pues se está apelando

edición en español de este excepcional estudio en todo el siglo XX (tiró 2,000 ejemplares). Venturosamente, el Instituto Nacional de Estudios Históricos de las Revoluciones de México está por ofrecer al público lector, con la Universidad Veracruzana, una nueva edición del libro de Knapp. Ver también, del propio Knapp, "The apocryphal memoirs of Sebastián Lerdo de Tejada", en The Hispanic American Historial Review, 31, 1, 1951. Knapp no supo de la existencia del prólogo incluido en este volumen. Sobre la Rectoría del Colegio de San Ildefonso, ver Ana María Cortés Nava, El Colegio de San Ildefonso y Sebastián Lerdo de Tejada, Rector (1852-1863), Tesis de Doctorado en Historia, Universidad Nacional Autónoma de México, Facultad de Filosofía y Letras, 1999. Sobre el papel de Lerdo en la Cancillería mexicana, ver Antonia Pi Suñer, Sebastián Lerdo de Tejada. Canciller/Estadista, 1989, México, Secretaría de Relaciones Exteriores. Sobre su administración en general está el libro, crítico, de su contemporáneo Vicente Riva Palacio, Historia de la administración de D. Sebastián Lerdo de Tejada, que escribe y publica antes de que concluya su mandato (1875, México, Imprenta del Padre Cobos). Sobre el hermano mayor de Sebastián, distinguidísimo liberal, ver Carmen Blázquez, Miguel Lerdo de Tejada. Un liberal veracruzano en la política nacional, 1978, México, El Colegio de México. 
al principio que reconoce en el pueblo la capacidad de darse otra forma de gobierno. Es una interpretación discutible que acaba provocando que se abra fuego. Porfirio Díaz, un general clave en la lucha contra la intervención francesa, no está de acuerdo con la Convocatoria. Tampoco lo está León Guzmán, quien había reclamado a Juárez, durante la intervención, la convocatoria a elecciones presidenciales ante la conclusión de su período constitucional, cosa que con razón Juárez rechazó, pues la lucha contra la intervención extranjera era una exigencia republicana superior a toda norma constitucional, cuya aplicación supusiera debilitar la acción militar y política contra el Segundo imperio. Era absurdo exigir elecciones en un país invadido por una fuerza extranjera. Con todo, la amenaza de un desorden político mayúsculo, si el gobierno de Juárez se empeñaba en organizar el plebiscito en 1867, llevó al presidente a retirar la propuesta. Ello echó por la borda la estrategia de Lerdo de Tejada para reformar la Constitución al final del Segundo imperio. Sin embargo, años después, cuando fue presidente de la República, volvió a la carga y logró, ahora sí, en 1874, introducir una serie de mecanismos constitucionales, incluido el que supone volver al esquema bicameral, fundamentales en la historia del constitucionalismo mexicano (el veto presidencial, la iniciativa presidencial, el carácter unicameral de la aprobación del presupuesto, etc.).

Hacia 1889, cuando Lerdo de Tejada muere, después de doce años de exilio en Nueva York, Díaz ya ha sido presidente en un primer mandato (1876-1880), ha dejado pasar el interregno de Manuel González (1880-1884), ha concluido su segundo mandato (1884-1888), y está en el arranque del tercero (1888-1892). A la muerte de Lerdo de Tejada, Díaz está plenamente consolidado en el poder y se ha impuesto la tarea de trasladar de inmediato los restos de Lerdo de Tejada de Nueva York a México, y darles sepultura en la Rotonda de los hombres ilustres. Díaz quiere ser magnánimo con el gran derrotado de Tuxtepec. No es claro que Lerdo de Tejada haya en vida deseado o accedido a ser trasladado a México después de su muerte. Todo indica que el cónsul Navarro, amigo de Lerdo de Tejada, se encarga de operar la orden que viene de México respecto de qué hacer de inmediato con los restos de don Sebastián. Al día siguiente de su muerte, el 22 de abril, su cuerpo 
es embalsamado y llevado a la capilla del cementerio de Marble, donde queda depositado provisionalmente hasta su traslado, dos semanas después, a México. El 3 de mayo, sus restos se conducen a la estación de ferrocarriles Pennsylvania Central, en Jersey City. Siete días más tarde, cruzan la frontera por El Paso. Ahí se pronuncia la primera alocución fúnebre ante los restos de Lerdo de Tejada en territorio mexicano. Dice Jesús Escobar y Armendáriz en Ciudad Juárez, el 10 de mayo de 1889:

Es Sebastián Lerdo de Tejada, cum maxima reverentia. Lerdo de Tejada, nombre aristócrata, no por la sangre, no por los pergaminos, sino por aquella aristocracia, única compatible con la República, la del talento. Ínclito ciudadano, sabio maestro, distinguido jurisconsulto, gran hombre de Estado. Hábil tribuno, a la fuerza de su palabra y elocuencia se debió la actitud decidida que asumió el Congreso Mexicano para resistir a la invasión francesa [...] El pueblo de Chihuahua os dice conmigo, agobiado de pesar, su último adiós. ${ }^{2}$

Pasa el cortejo fúnebre, con los honores de Estado, por Chihuahua, Zacatecas, Aguascalientes, Encarnación, Irapuato, Celaya, Querétaro, Tula. Se le recibe con gran pompa en la estación central de la ciudad de México. Se le lleva a la Cámara de Diputados, en donde se pronuncian discursos laudatorios, y después se le traslada a la Rotonda de los hombres ilustres en el panteón de Dolores, en donde se pronuncian nuevas piezas oratorias. El porfirismo decide de inmediato publicar un libro oficial con todos los discursos, con una descripción de lo sucedido en cada una de las ciudades por las que pasó el cuerpo de Lerdo de Tejada, e incluye una nota biográfica. El régimen porfirista consolidado se ostenta generoso al rendir homenaje "a tan insigne ciudadano": "entre los hombres de la Reforma, Lerdo de Tejada es, por excelencia, el hombre del derecho, el hombre de la ley", reconoce sin rubor el documento.

2 "Alocución fúnebre pronunciada por el C. Jesús Escobar y Armendáriz, ante los restos del C. Sebastián Lerdo de Tejada, al pasar por Ciudad Juárez (Paso del Norte), el 10 de mayo de 1889", Archivo Familiar de Abelardo Escobar. 
En el capítulo llamado "apunte biográfico", el libro no entra a fondo a la cuestión tuxtepecana, obviamente, pero está obligado a tocar el tema por lo menos para explicar por qué Lerdo de Tejada acabó viviendo doce años en Nueva York. Y lo menciona del modo más circular, al argumentar que no ha pasado suficiente tiempo, ya no digamos para valorar lo sucedido en la Revolución de Tuxtepec (1876): ni siquiera "es hora aún de apreciar la administración del Sr. Lerdo” (¡1872-1876!). Es decir, el análisis biográfico se interrumpe en la presidencia lerdiana de la Suprema Corte de Justicia. Y ya muy al final se agrega esto:

Triunfante la Revolución de Tuxtepec, tuvo el Sr. Lerdo que salir de la ciudad de México, acompañado de sus Ministros Romero Rubio, Escobedo y Baz, y de otros pocos amigos, en la noche del 20 de noviembre de 1876. Desde entonces vivió en Nueva York, entregado por completo a sus estudios de legalista y a negocios particulares, sin procurar intervenir en las cuestiones políticas de su país. En Nueva York ha muerto el 21 de abril de este año, víctima de una bronquitis capital aguda que lo llevó al sepulcro en menos de tres días. Se refiere que deja escritas sus Memorias.

El libro oficial sobre las exequias, que llevó por título Sebastián Lerdo de Tejada, 1823-1889. In Memoriam (1889, México, Tipografía de El Partido Liberal), nos da una pista muy valiosa para los propósitos de este ensayo. Se afirma, efectivamente, al final de la última cita, que Lerdo de Tejada ha dejado escritas unas Memorias. Nótese sin embargo el lenguaje: dice "Se refiere que deja escritas sus Memorias", es decir, que al que escribe no le consta que existan dichas Memorias, sino que ha escuchado, o se le ha dicho, que Lerdo de Tejada, digamos, "las dejó escritas". No se dice quién "refirió" tal cosa. Pudo ciertamente ser el cónsul Navarro, quien visitaba con frecuencia a Lerdo de Tejada. Quizá alguien más, de trato cercano al ex-presidente. En todo caso, nada de eso se dice. ¿Dónde habían quedado, finalmente, las tales Memorias?

La pregunta se respondería muy pronto. A finales de 1889 empezarán a publicarse, por entregas, las Memorias de Sebastián Lerdo de Tejada en el periódico El Mundo, de Laredo, Texas, y circularán profu- 
samente en el norte de México. El Mundo publicará de inmediato las entregas juntas como libro (1890, Laredo, Tipografía de El Mundo). El hijo del Ahuizote publicará en México fragmentos de la obra. Porfirio Díaz recién ha homenajeado a Lerdo de Tejada y de inmediato intenta todo para evitar la distribución de sus Memorias, el más venenoso libelo contra su persona, contra sus hombres más cercanos y contra su gobierno. Los porfiristas actuaron, por supuesto, y de inmediato: Ignacio Martínez, director del periódico El Mundo y a la sazón antiguo general adversario de Díaz, es asesinado en Laredo, Texas, poco después de la publicación de las Memorias. ${ }^{3}$ El nuevo régimen manda un mensaje claro a quienes osen publicar esos execrables libelos antiporfiristas dentro o fuera de México. No será sino hasta cinco años después, cuando se conozca una nueva edición del libro, obviamente del otro lado de la frontera, bajo el sello de la Tipografía El Porvenir, en Brownsville, Texas, en 1895, y otra edición, tres años más tarde, en 1898, por la misma casa editora. Siete años después, en 1905, la Tipografía La Libertad, de San Diego, California, volverá a publicar la obra. El libro tuvo, por lo tanto, cuatro ediciones desde que se imprimió hasta la Revolución. En el arranque de la Revolución, tuvo siete ediciones (1910-1912). Sólo en 1911 fueron cinco (cuatro mexicanas y una texana). El texto logró circular, con enormes dificultades, antes de la Revolución. Todo indica que Díaz pudo evitar, durante su larga dictadura, que el libro se publicara o circulara en México. Sin embargo, apenas estalló la Revolución, la pequeña obra vivió su auge editorial. (Véase el cuadro al final del texto, que enlista las ediciones identificadas de las Memorias de Sebastián Lerdo de Tejada.)

Durante muchos años, el porfirismo descalifica la obra con el argumento de que no ha sido escrita por Lerdo de Tejada. Se dice que las Memorias son apócrifas. Así, el gobierno de Díaz cambiaba su argumentación respecto de las Memorias, porque en el libro oficial se afirmaba que Lerdo de Tejada había dejado escritas sus Memorias, y después - a la vista aparente de la rudeza de las críticas contenidas ahí a la persona y la obra de Porfirio Díaz- alegaba que no eran

${ }^{3}$ Frank A. Knapp, op. cit. 
auténticas. Alguien informó que venían unas Memorias, y así se consignó en el libro oficial de homenaje, pero ese alguien no avisó que las Memorias eran una bomba contra Díaz. Un dato adicional: en la primera edición, Ignacio Martínez, director de El Mundo, afirma que las Memorias llegaron a la redacción del periódico gracias a una persona que residía en los Estados Unidos y que había tenido una estrecha relación con el ex-presidente. Por lo tanto, es probable que, quien anunció al gobierno de Díaz que Lerdo de Tejada había escrito unas Memorias, las haya enviado después a El Mundo. De cualquier modo, el editor no negaba la autenticidad de la obra, al tiempo que protegía la identidad de la persona que había llevado al periódico el texto, residente en los Estados Unidos y con una relación estrecha con el difunto.

Por otro lado, se decía que Lerdo de Tejada no había tenido nunca afanes de escritor, que le costaba escribir, aunque el estilo especialmente mordaz del autor del libro coincidía con el modo de hablar del ex-presidente y la cantidad de referencias precisas a la vida de Lerdo de Tejada en Nueva York hacía pensar naturalmente en la autenticidad de su autoría.

En el mismo libro oficial, publicado poco después de las exequias de Lerdo de Tejada, se reprodujo un texto, escrito por uno de sus amigos, que ofrecía una pista. Dice así el capítulo titulado "Últimos días del Sr. Lerdo":

Uno de los amigos del Sr. Lerdo, que tuvieron la fortuna de visitarlo con frecuencia en Nueva York, el Sr. D. Gonzalo A. Esteva, dice lo que sigue: El Sr. Lerdo vivía muy retirado en Nueva York. Al llegar allí se instaló en el suntuoso Hotel Windsor, en magníficas habitaciones del primer piso. En ellas le servían la comida, pues nunca bajaba a los comedores del hotel. El ruido y el bullicio de aquella especie de caravansary norteamericano no le agradaba y, por otra parte, él deseaba llevar una existencia confortable, pero modesta, y allí, por las habitaciones espléndidamente decoradas y repletas de lujosos muebles que ocupaba, le cobraban cien pesos diarios. Pronto encontró un boarding, elegante y aristocrático, pero tranquilo y asociado a sus deseos, y ahí se instaló. Cuando el boarding, o casa de huéspedes, se trasladó a los dos años a Lenox House, el Sr. Lerdo lo siguió, y allí ha muerto. 
En el verano, el Sr. Lerdo se levantaba entre once y doce del día. Un peluquero cubano entraba a su recámara a afeitarlo. En seguida tomaba un baño, se vestía, se desayunaba, y tomando un libro bajo el brazo, se dirigía a la isla Conney, por el vapor que parte cada dos horas del ferry 40. Llegando ahí se sentaba en la playa inmediata a la orilla a contemplar las azules y tranquilas ondas del océano; a ratos meditaba, a ratos leía. Llegada la hora del lunch, tomaba un refrigerio de dos o tres platos en el magnífico restaurant de Brighton, y a las cinco o seis de la tarde, regresaba a Nueva York. Por la noche, a la siete, solía dar un paseo a pie, que duraba una hora, por la $5^{\text {a }}$ Avenida, la Calle 14, la Calle 23 y Broadway, en el cuadro formado por esas calles [...] A las ocho de la noche el Sr. Lerdo volvía invariablemente a su habitación y se ponía a escribir o a despachar algunos negocios propios o encomendados a su dirección de abogado, ya por mexicanos, ya por extranjeros, que siempre tuvieron motivo de alabarse de haberle encomendado aquéllos. En el invierno cambiaba su sistema de vida el Sr. Lerdo, así como las horas de sus paseos a pie. Días había en que el frío excesivo lo retenía dentro de sus habitaciones, al lado de los caloríferos.

Las visitas escasas que tenía de personajes extranjeros y mexicanos que llegaban a Nueva York o que residían allí, las recibía generalmente de nueve a diez de la noche, o los domingos en la tarde [...] Hablaba el inglés correctamente y lo escribía con la misma perfección. Lo había aprendido en su destierro. Así, leía diariamente los diarios americanos, los libros nuevos y todo lo que podía tener algún interés.

Así pues, Lerdo de Tejada escribía en Nueva York, según su amigo Esteva. ¿Sólo escribía sobre los asuntos que llevaba como abogado o también escribía sus Memorias? Nada fortalece la percepción de que la personalidad de Lerdo de Tejada no fuese compatible con la escritura y, en su circunstancia, era perfectamente entendible que escribiera unas Memorias. Daniel Cosío Villegas, uno de los estudiosos más acuciosos del ex-presidente, registra entre los observadores de la época un "consenso cabal en considerarlo como hombre de extraordinario talento y saber. Se admite su rectitud. Alguien le reconoce ser hombre de carácter, aunque la mayoría lo pinta débil con sus amigos, con sus amigas, y con la comida y la bebida. También hay concordancia general, o casi general, en tenerlo como hombre orgulloso, muy consciente de su propio 
valer y poco inclinado a tomar en serio las opiniones ajenas". Algunos, dice Cosío Villegas, lo pintan "escéptico", otros "sin tacto político", y otros lo perciben, en el extremo, "soberbiamente orgulloso". No sería por lo tanto sorprendente que un hombre así, derrotado políticamente y en el exilio, quisiera señalar críticamente a sus adversarios y explicar su circunstancia y los móviles de su conducta en unas Memorias que pusieran en claro el papel que él había jugado en esos años de protagonismo político. El propio Cosío Villegas recupera el siguiente "valioso retrato" de Lerdo de Tejada en el Congreso, escrito por Justo Sierra, uno de los más destacados intelectuales del porfirismo, en Juárez. Su obra y su tiempo:

Era, sin quererlo, sin conocerlo, el tipo de orador nuevo. Frecuentemente enfático, sus discursos eran bajorrelieves de bronce. El bronce era la lógica, una inflexible lógica de que se servía a maravilla para censurar los textos y para desarmar y vencer a las personas. No envolvía su idea en grandes metáforas sonoras como los retóricos o los poetas de la tribuna; iba al grano; no citaba a los clásicos como su frecuente adversario el licenciado Montes, que hacía discursos en latín con notas en castellano, ni hacía de la Historia una espada de fuego, como Altamirano; citaba las palabras de las iniciativas o proposiciones a discusión, las comparaba, las analizaba con su poder dialéctico de primera fuerza. Y no era frío; su palabra y su voz se enardecían, y su concepto fulguraba en cada conclusión. ${ }^{4}$

Frank Knapp, su biógrafo, subraya, en la caracterización que hace del personaje, su formación jesuita, su extraordinaria disciplina en el trabajo, su excepcional inteligencia, la precisión de sus conceptos, su soberbia intelectual, el carácter cáustico de sus ironías y sarcasmos, su devoción por los libros en su vida como estudiante, profesor y rector. ¿Era fácil imaginar a alguien así escribiendo unas Memorias en el exilio? Por supuesto que sí. ${ }^{5}$

${ }^{4}$ Daniel Cosío Villegas, "Sebastián Lerdo de Tejada, mártir de la República Restaurada", en Historia mexicana, XVII, 2, 1967.

${ }^{5}$ José Fuentes Mares nos prueba que, por lo pronto, cartas sobre sus males de amor sí que escribía Don Sebastián. Ver el curioso libro, del propio Fuentes Mares, Don Sebastián Lerdo de Tejada y el amor, 1972, México, Fondo de Cultura Económica. 


\section{Rogaciano en Nueva York}

Sin embargo, toda la evidencia dice que no: Lerdo de Tejada nunca escribió sus Memorias. Una vez que estalla la Revolución mexicana, el 20 de noviembre de 1910, el libro empieza a reeditarse profusamente en México. Hay cinco ediciones de las Memorias solamente en 1911, y el verdadero autor, que se encuentra en una situación económica especialmente lastimosa, a sus 56 años, empieza a reclamar sus derechos autorales y, claro, su reconocimiento público. Hacia 1911, es cada vez más fuerte el rumor de que, finalmente, ha aparecido el verdadero autor, quien se reconoce como tal. El primer documento que prueba que Sebastián Lerdo de Tejada no escribió las Memorias de Sebastián Lerdo de Tejada es una carta fechada el 14 de junio de 1912, escrita en Los Ángeles, California, por un periodista jalisciense, furioso antiporfirista en el exilio desde 1886. Es Adolfo Rogaciano Carrillo, quien había coincidido con Lerdo de Tejada en Nueva York durante casi todo el año de 1886. La carta de Rogaciano está dirigida a Juan Sánchez Azcona, secretario particular del presidente Francisco I. Madero, en la que el remitente pide al gobierno un cargo en el consulado de Los Ángeles o San Francisco, alegando ser él quien escribió las Memo-

124 rias y ser precursor del movimiento revolucionario. Y sí: todo indicaba que poco menos de un año de conversaciones de Lerdo de Tejada con Adolfo Rogaciano Carrillo, había bastado, en 1886, para reunir el material para unas Memorias de furioso antiporfirismo por partida doble.

Carrillo morirá a los 71 años, en 1926, 37 años después de la primera edición de las Memorias y tras 40 años de exilio permanente y definitivo, como el de Lerdo de Tejada. Carrillo nunca regresó a México. En 1886, su actividad periodística le valió el exilio en Nueva York, pero en 1887 viajó a La Habana y después a Europa (Madrid, París) para poco después regresar a Nueva York, vivir muchos años en San Francisco y finalmente en Los Ángeles. Hacia 1912, al solicitar empleo y demandar reconocimiento, Carrillo lleva viviendo 26 años en el exilio, casi siempre en la miseria. Periodista y editor, Carrillo pierde su imprenta en el terremoto de San Francisco en 1906 y ve morir, en aquella 
catástrofe, a su única hija. Da clases de español. Escribe cuentos para revistas y periódicos californianos. Se defiende como puede. En la misma carta fechada en 1912, afirma que su mujer se encuentra enferma. En el arranque de la Revolución mexicana, volver a México ya no tiene sentido para Carrillo. Pero, se insiste, quiere que el gobierno revolucionario premie sus servicios antiporfiristas con un empleo en los Estados Unidos.

Por otro lado, Carrillo alega ante Sánchez Azcona haber sido, en México, acérrimo enemigo de Porfirio Díaz, haber escrito artículos en su contra, haber sido sentenciado por el delito de sedición, haber estado preso en la cárcel de Belén, en la ciudad de México, y haber sido desterrado del país en 1886. Después, en el exilio "publiqué -afirma- las Memorias en una serie de artículos que mandé a El Mundo, periódico dirigido por el General Ignacio Martínez, quien fue víctima de Bernardo Reyes". ${ }^{6}$

Quince días después, el 1o. de julio de 1912, Carrillo escribe al presidente Madero una carta que dice así:

Sr. Don Francisco I. Madero

Presidente de la República

Muy respetado señor Presidente:

Tres de los mejores amigos y partidarios de usted, como lo son los Sres. Juan Sánchez Azcona, Manuel Calero y Rafael Hernández, han hablado a usted a favor mío, interesándose bondadosamente por mi suerte. El primero de dichos señores [...] me manifiesta que usted tiene y ha tenido la mejor voluntad para conmigo, y que ud. le recomienda mi asunto al Sr. Ministro de Relaciones, Don Pedro Lascuráin. Agradezco a ud. infinito los generosos sentimientos que abriga para conmigo, a los cuales he correspondido, anticipándolos en artículos publicados en periódicos [...] Opino que si el Sr. Lascuráin toma empeño en atender las indicaciones de ud., le sobrarán medios para emplearme en California al servicio del Gobierno, pues además de ser miembro de la P. A. de los Estados Unidos, escribo y hablo tres idiomas modernos, como lo son el español, el francés y el inglés. ${ }^{7}$

${ }^{6}$ Reyes era gobernador de Nuevo León y hombre cercano a Porfirio Díaz.

${ }^{7}$ Estas cartas se encuentran en el Archivo General de la Nación, Fondo Documental Madero, carpeta 288-1, caja 12 y carpeta 33, caja 2. 
La correspondencia posterior entre Carrillo y Sánchez Azcona sugiere que ya están llegando a un acuerdo respecto del cargo en el consulado, cuando el presidente Francisco I. Madero es asesinado en febrero de 1913. Se esfumaba así la posibilidad del cargo. Finalmente, será el jefe del ejército constitucionalista, Venustiano Carranza, quien, poco después, el 1o. de marzo de 1914, nombre a Adolfo Rogaciano Carrillo "Cónsul de México en Los Ángeles, Cal., Estados Unidos de América, con el sueldo anual de dos mil quinientos cincuenta y cinco dólares; cuota diaria, siete dólares". ${ }^{8}$ No pasará mucho tiempo, sin embargo, para que Carrillo se meta en problemas. En mayo de 1915, un reporte de Antonio Villarreal, funcionario de la Cancillería, da aviso a la misma del estado que guarda la agenda del cónsul Carrillo. El argumento de Villarreal era que no podía tenerse como cónsul a Carrillo por el único mérito de haber escrito las Memorias, pues el señor había, en unos cuantos meses, entrado en conflicto con sus colaboradores, poniendo en riesgo las labores de la oficina, y había tomado graves decisiones sin consultar a la Cancillería. Dice Villarreal:

Todos los que formamos la nueva generación mexicana, al leer el folleto titulado Memorias de Sebastián Lerdo de Tejada, que tan profusamente circuló en las postrimerías de la dictadura del General Porfirio Díaz, lo acogimos con aplauso [...] porque en sí constituía propaganda revolucionaria, porque ya todos los espíritus jóvenes ansiábamos orientación hacia un cambio político que redimiera aquella sociedad llamada a ser feliz, y que permanecía en la más completa de las esclavitudes y de las abyecciones. Los ataques satíricos lanzados al Tirano en esas Memorias nos cautivaron y nos llenaron de ira contra aquel régimen que tanto deprimió el espíritu patrio. La voz del público señala a Adolfo Carrillo, actual cónsul del Gobierno Constitucionalista en la Ciudad de los Ángeles, California, como autor, y él así lo declara.

Sin embargo, dice Villarreal en 1915 que hay que observar con objetividad la conducta del cónsul como tal, “dejando para su oportu-

${ }^{8}$ Ibid. 
nidad el considerar el valor y mérito de la producción literaria de Carrillo”. Sigue Villarreal:

A la edad de 20 años, formando parte del personal de redacción de un periódico editado en la ciudad de México, lanzó un artículo candente contra la labor de Porfirio Díaz en 1886, que le valió cárcel. Concluida su condena vivió en el extranjero y siendo empleado de la casa editora de libros en Nueva York, Appleton y Cía., conoció al ilustre mexicano Don Sebastián Lerdo de Tejada, de quien recibió favores personales. Su vida hasta el año de 1914 se redujo a una simple lucha por la existencia, dando clases de español y escribiendo cuentos para algunos periódicos publicados en español en los Estados Unidos. En ese año lo encontramos escribiendo en un periódico que se llama La Prensa, editado en la ciudad de Los Ángeles, California. Por entonces, encontrándose vacante el Consulado de México en esa ciudad, por gestiones de su amigo el Licenciado Heriberto Barrón, logró ser nombrado cónsul, el primero de marzo de 1914. ¿Cuál ha sido su labor? Funesta [...] Bien sabido es que este puesto se la ha conferido como recompensa a su destierro, y a su labor en contra del Tirano Porfirio Díaz, como autor de las Memorias de Don Sebastián Lerdo de Tejada. Que se le pensione pero que no siga comprometiendo a México. ${ }^{9}$

Quién sabe si Villarreal es objetivo porque tiene interés en los asuntos que analiza. Le critica a Carrillo, por ejemplo, el manejo discrecional que hace de permisos de pesca, sin consulta alguna con la ciudad de México. Hay problemas con las compañías de telégrafos que no atiende. En fin. El hecho es, de cualquier modo, que Carrillo pierde el empleo hacia 1916, año en que es atropellado en San Francisco. No será sino hasta el gobierno de Álvaro Obregón (1920-1924) cuando Carrillo tenga en el mismo consulado "un empleo honorífico, habiéndole pasado una mensualidad de ciento cincuenta a ciento ochenta dólares para sus gastos". ${ }^{10}$ Después, el 16 de marzo de 1925, Carrillo, ya en la vejez, es nombrado "Escribiente de Segunda" en el propio consulado de Los Ángeles,

${ }^{9}$ Expediente de Adolfo Rogaciano Carrillo en el Archivo Histórico de la Secretaría de Relaciones Exteriores, P1130297-P1130450.

${ }^{10} \mathrm{Ibid}$. 
en el arranque del gobierno de Plutarco Elías Calles (1924-1928). Poco después, el 5 de abril de 1926, Carrillo, cinco meses antes de morir, a los 71 años, le escribe una carta a su jefe, el cónsul, ahí mismo en Los Ángeles, en donde le dice:

Señor Don Alfonso Pesqueira

Cónsul de México en Los Ángeles, California

Muy estimado amigo:

No es por espíritu de vanidad ni de jactancia, sino como un deber sagrado para la posteridad, he creído oportuno el que se publique una nueva edición de las Memorias de Lerdo de Tejada que, como dijo usted con atingencia, contribuyeron tanto a nutrir el espíritu revolucionario de la briosa juventud, que más tarde se levantara airada contra los ídolos del viejo régimen porfiriano. Habiendo formado usted parte integrante de esa juventud revolucionaria, juzgo que bondadosamente, como lo tiene de costumbre, ejercerá su influencia cerca de nuestro Gobierno para que dichas Memorias sean reimpresas, para cuyo efecto he escrito un prólogo informativo de cómo aconteció que yo las escribiera, pues es generalmente sabido que yo residí por espacio de nueve meses al lado del señor Lerdo, quien en conversaciones varias, tuvo oportuno el hacerme interesantes y verídicas revelaciones, que felizmente yo fui hábil al cristalizar en dichas Memorias. Mucho de lo que yo omití entonces aparece en el prólogo, que tengo la certidumbre de que revestirá palpitante interés [...] Quedo de usted subalterno y amigo. ${ }^{11}$

Todo indica, por lo tanto, que Lerdo de Tejada no dictó sus Memorias a Adolfo Rogaciano Carrillo; de lo contrario, Carrillo lo afirmaría con toda claridad y contundencia. Nada indica que Lerdo de Tejada conversaba con Carrillo sabedor de que su interlocutor preparaba unas Memorias. Nada indica que Carrillo tomaba notas mientras Lerdo de Tejada le contaba cosas en Nueva York. Más bien parece que el periodista antiporfirista, con especial olfato periodístico, conversa con el antiporfirista número uno de México, y acaso teme que Lerdo de Tejada rechace la idea de que de las conversaciones emerjan unas Memorias. Por ello

${ }^{11}$ Ibid. 
registra seguramente lo dicho día a día por Lerdo de Tejada, ya en la soledad, al final de cada velada, pues se confiesa "hábil en cristalizar" en las Memorias esas "revelaciones interesantes y verídicas" que surgen de las conversaciones entre ambos. ¿A qué otra "habilidad" pudo referirse? ${ }^{12}$

En todo caso, ¿por qué no reveló Carrillo su autoría desde $1889 ?$ Seguramente porque era peligroso para su vida. La prueba está en que el director de El Mundo fue asesinado poco después de publicar las Memorias, hecho que Carrillo atribuyó a Bernardo Reyes como autor intelectual. Muchos años después, en 1926, Carrillo se duele en su prólogo de que la viuda de Ignacio Martínez, director de El Mundo, al publicar las entregas como libro en 1890, no le haya pagado regalías. Acaso no lo hizo la viuda porque la factura política de su publicación había sido pagada por su marido, no por el autor. Y fue la factura más cara: Martínez perdió la vida por haber publicado la obra de Carrillo. Nada sugiere que Carrillo haya reclamado regalías en la víspera de la publicación y ulterior asesinato de Martínez, por razones éticas y pragmáticas. Lo hace muchos años después, en 1926, ya muy mayor, con cierta amargura e insensatez. De un modo u otro, no aparecer como autor en la primera edición salvó su vida, pero impidió ser cabalmente valorado como creador de una obra que muchos juzgarán valiosa como precursora del movimiento revolucionario (así la vieron, en el arranque de la Revolución, nada menos que Francisco I. Madero y Venustiano Carranza). ${ }^{13} \mathrm{Y}$, claro, el modo de salvar la vida también imposibilitó el cobro de regalías frente al auge de ediciones posteriores al inicio de la Revolución. En la carta de Carrillo al cónsul Pesqueira, el remitente pide al destinatario que se publique una nueva edición de las Memorias, junto con el prólogo anunciado que, sin duda -el olfato del periodista otra vez- revestiría "palpitante interés".

${ }^{12}$ La hipótesis de que Lerdo escribió sus Memorias y después Carrillo se atribuyó tramposamente su autoría quedó descartada en 1951 por Knapp, el biógrafo de Lerdo, quien encuentra en ellas datos imprecisos (fechas importantes, lugares clave, etc.) que Lerdo simple y llanamente no pudo olvidar.

${ }^{13}$ Por su lado, Emiliano Zapata "se moría de risa releyendo los pasajes más chuscos de las Memorias de Lerdo". Enrique Krauze, Emiliano Zapata. El amor a la tierra, 1987, México, Fondo de Cultura Económica, p. 94. 
En una palabra: Carrillo quiere en 1926 una reedición de las Memorias que sea auspiciada por el gobierno de Calles y que incluya su prólogo para que se le reconozca, ahora sí formalmente, un lugar en la historia del movimiento revolucionario y, claro, para cobrar por primera vez alguna regalía. Era seguramente el último intento. El gobierno de Calles acepta el proyecto de reedición. Carrillo envía de inmediato un presupuesto para su análisis y eventual aprobación. ${ }^{14}$ Sin embargo, un poco más de cuatro meses después, es decir, el 23 de agosto de 1926, Adolfo Rogaciano Carrillo muere en Los Ángeles. La Cancillería mexicana acabó cancelando el proyecto del libro y archivó, en el expediente correspondiente de personal, la solicitud de Carrillo junto con su prólogo. Dicho prólogo no se rescató del expediente de Carrillo en los archivos de la Cancillería sino hasta 34 años después, en 1960, cuando es publicado por la prestigiada revista Historia mexicana, de El Colegio de México, por iniciativa del historiador estadounidense Stanley Ross. Sin embargo, el prólogo de las Memorias se publicó separado de las Memorias (!) de modo que el lector nunca pudo leer el prólogo junto con la obra. ${ }^{15}$ Parece increíble pero es cierto: la obra (1889) y su prólogo (1926) estuvieron siempre separados. Nunca se publicaron las Memorias de Sebastián Lerdo de Tejada, escritas por Carrillo, junto con el prólogo del propio Carrillo, sino hasta ahora, cuando se cumplen 100 años de la explosión de ediciones mexicanas de las Memorias de Sebastián Lerdo de Tejada.

Ha pasado un siglo y sólo existen, de pequeño tiraje, dos ediciones posrevolucionarias de las Memorias: una es veracruzana, de Editorial Citlaltépetl, con prólogo de Leonardo Pasquel, publicada en 1959 (600 ejemplares); la otra es tabasqueña, del Consejo Editorial del Gobierno de Tabasco, con prólogo de José Bulnes, de 1980 (3,000 ejemplares). Sorprendentemente, ninguna de las dos ediciones publica el prólogo de Carrillo, pese que, en su estudio, Pasquel dice haberlo consultado en los archivos de la Cancillería mexicana, y el estudio de Bulnes está basado, todo, en lo afirmado por Pasquel. En otras palabras, y en perspectiva histórica: llama la atención que por una u otra razón, el prólogo

${ }^{14}$ Expediente de Adolfo Rogaciano Carrillo, op. cit.

${ }^{15}$ Adolfo Carrillo, "Prólogo a las 'Memorias' de Lerdo", Historia mexicana, 37, X, 1, 1960. En ese mismo número se publicó, de Stanley Ross, un breve "Prólogo a un prólogo". 
no se haya encontrado nunca con su libro. Por primera vez, ahora, en 2011, se hace realidad el sueño de Carrillo: se publican las Memorias, ya reconocida plenamente su autoría, junto con su "palpitante" prólogo. Sirva este ensayo como homenaje a este singular periodista mexicano, terco adversario de Porfirio Díaz, el dictador.

\section{Carrillo contra Porfirio}

¿Qué sucedió para que Carrillo se convirtiera en ese terco adversario del dictador? El periodista Carrillo abandona el país en febrero de 1886 y se va a Nueva York. Estamos en el inicio del fin del llamado tuxtepecanismo: comienza propiamente la dictadura de Díaz. Carrillo opta por el exilio diez años después de iniciado el exilio de Lerdo de Tejada, en la misma urbe de hierro. Carrillo abandona el país mes y medio después de salir de la cárcel. Sus escritos en contra del primer gobierno reelecto de Díaz han puesto en riesgo su vida. Tiene entonces 31 años. Se va soltero.

La primera clave para una biografía política de Adolfo Rogaciano Carrillo nos la ofrece Daniel Cosío Villegas en su magna Historia moderna de México (1970). Al momento de analizar el final de la administración del presidente Manuel González (1880-1884), Cosío Villegas detecta una red de periodistas gonzalistas que "censuran a Porfirio como medio de halagar a González" ${ }^{16}$ Carrillo en su Correo del Lunes, de un modo "directo o indirecto", dependía - nos dice Cosío Villegas- "del favor oficial" del gobierno de González. Fausta Gantús, la acuciosa estudiosa de la vida de Carrillo en aquellos años mozos, va más allá de la hipótesis de Cosío: no interrumpe en el gonzalismo su visión de Carrillo y afirma que en realidad Díaz, en el arranque de la dictadura, tiene que dar ya un manotazo fuerte al periodismo crítico, y el manotazo se lo va a llevar Carrillo. No sólo Carrillo, es cierto, pues Enrique Chávarri (apodado "Juvenal") sufrió la misma persecución en esa coyuntura. Pero la figura de Carrillo tiene especial importancia porque

${ }^{16}$ Historia moderna de México, 1970, México, Editorial Hermes, tomo IX, Vida política interior, p. 707. 
acabó siendo el símbolo del periodismo en el exilio en la primera parte de la dictadura de Porfirio Díaz. ${ }^{17}$ Fausta Gantús dice con razón que Carrillo "sintetiza, como pocos, los múltiples y variados mecanismos de control y de censura" que inaugura Porfirio Díaz al final del tuxtepecanismo. Lo importante, sin embargo, para el vuelco que dará la vida de Carrillo, es que a partir de entonces, es decir, a partir del arranque de su exilio, se entenderá a sí mismo como el más decidido defenestrador del régimen de Porfirio Díaz. Y dedicará los próximos cuatro años de su vida a esa causa. Lo hará apasionadamente. Los largos años de la dictadura, sin embargo, irán apagando esa pasión antiporfirista. El extenso período de lejanía lo aísla del contexto mexicano. Con el correr de los años, Carrillo es olvidado por los círculos periodísticos de la capital de la República.

La vida de Carrillo es apasionante y compleja, pues no admite juicios simples. Algo que gravita todo el tiempo sobre la vida de Carrillo es la crítica que le hacen, tirios y troyanos, a la dudosa ética con que ejerce el oficio periodístico. Ciertamente se le tiene por periodista de fina y venenosa pluma, se le entiende arrojado oposicionista y en general osado crítico. No se le regatea valor ni capacidad argumentativa ni retórica. Se le teme por su estilo punzante. Pero también se le percibe excedido, por ejemplo, en su invasión constante de la esfera privada de las personas (se lió a golpes decenas de veces y en dos ocasiones se batió en duelo contra indignados caballeros ante el ultraje del honor de alguna dama por la ilimitada mordacidad de su pluma). En 1881, a sus 24 años, colabora para El Lunes y una noche es atacado a puñaladas cerca del Portal de Mercaderes. El director del periódico sale en su defensa pero, sabedor de que el ataque es en represalia a algún exceso muy Rogaciano, dice, en El Lunes del 2 de mayo de 1881:

Con motivo de la agresión de que ha sido objeto nuestro colaborador Adolfo Carrillo, creemos oportuna la siguiente aclaración: cuando en los

${ }^{17}$ Fausta Gantús, "La oposición con nombre y apellido: Adolfo Carrillo. Alianzas y complicidades, represión y exilio", en Adriana Pineda Soto, (coord.), Plumas y tintas de la prensa mexicana, 2008, Morelia, Universidad Michoacana de San Nicolás de Hidalgo. Ver también, de la misma autora, su extraordinario ensayo "Díaz de nuevo presidente. La deuda inglesa, la prensa y la implementación de la política represora" (2004), en www.historiadoresdelaprensa.com.mx. 
artículos de colaboración se contienen ciertos ataques [el periódico] ha requerido y seguirá requiriendo las firmas de los autores al publicarlos, para evitar que en las cuestiones personales a que den origen, se le atribuya ninguna clase de solidaridad. Esto no nos impide por supuesto extrañar y reprobar que a un compañero de la prensa, sea quien fuere, se le asalte en la calle como si no hubiere medios de satisfacer las injurias en el terreno de los caballeros. ${ }^{18}$

El director asume que no hay razones políticas en la agresión a Carrillo, sino otras derivadas del abordaje de "cuestiones personales" que, eventualmente, terminan en "injurias". El periódico advierte que, en esos casos, no ofrece solidaridad a sus colaboradores agredidos. Ese exceso, sin embargo, sería peccata minuta si no se viese acompañado de otros, que hacen un cuadro: se le señala como mentiroso; sus amigos de la juventud jalisciense salen a desmentirlo cuando ya en la ciudad de México dice haber nacido en Toluca (Estado de México) cuando nació en Sayula (Jalisco), o dice que nació en 1866 cuando nació en 1855, o afirma que en Europa estuvo en Madrid y París (cosa probada), pero también en Berlín y en Londres (cosa a todas luces inventada). Por otro lado, se le señala, con frecuencia, desde muy joven, como periodista chantajista que amenaza con publicar determinadas críticas o contenidos a cambio de paga por dejar quieta la pluma. Dice Manuel Puga y Acal:

Supe que a cierto ministro de México en el extranjero cuya mujer era ligera de cascos, Carrillo le había substraído una fuerte suma, amenazándolo con publicar una aventura amorosa de su consorte; y a un joven de la alta sociedad, amigo mío que estaba a punto de casarse con una rica heredera, le sacó algunos centenares de pesos por no relatar en su semanario los detalles algo escandalosos con cierta juerga juvenil que habíamos corrido. ${ }^{19}$

También se le juzga persona tramposa: en sus Memorias, Victoriano Salado Álvarez dice que Carrillo "no carecía de talento, aunque resultara

${ }^{18}$ Citado por Gantús, op cit.

${ }^{19}$ Excélsior, 15 de marzo de 1926, p. 5. 
después un truhán desaforado; queriendo jugar una mala partida a los de la Alianza Literaria, les mandó una composición en verso que al parecer era de autor conocido. Hicieron notar el plagio otros periódicos". ${ }^{20}$

Para todo, sin embargo, tenía respuesta Carrillo. A los que lo acusaron de plagio les dice: "Muchachos. Yo los creía más astutos", y alega que lo que intentaba con el juego era ver qué tan al corriente estaban "de las cosas del mundo". ${ }^{21}$ A los que lo acusan de meterse en la vida privada de las personas les dice: "Yo no ataco por sistema, ni aspiro a esa popularidad callejera que surge muchas veces de los escándalos". ${ }^{22}$ Él alega una y otra vez que sus adversarios inventan historias para desprestigiarlo por su postura crítica de la conducta de funcionarios y políticos. "Acostumbrados a saborear la adulación [...] se indignan y tascan el freno cuando un periódico les dice: ¡Alto! ¡Se llevan ustedes, por distracción, los fondos públicos!". Las críticas, especialmente la relacionada con la presunta inclinación chantajista de Carrillo, se escucharán no sólo en México, antes del exilio, sino también en La Habana, en donde vivió y practicó su profesión. El tema de su moral periodística gravita sobre la vida de Carrillo: en el prólogo a las Memorias, escrito apenas unos meses antes de morir, en 1926, él mismo saca el tema y les dice a sus críticos "fósiles de gangrenados cerebros", a "esos condottiéres de albañal" que lo acusan "de haber hecho chantaje" tanto en el Porfiriato como en la primera etapa revolucionaria:

¡Qué imbéciles! Si yo hubiera ejercido ese sistema, en el cual ellos han sido y son maestros, habría llegado a ser senador porfiriano y hoy un capitalista manchado de pie a cabeza, pero rico al menos. Mas careciendo de esa virtud chantajista, muy propia de reaccionarios y de científicos, hoy vivo en la pobreza, lo que es un crimen para los hombrecillos nacidos al calor de los asesinatos de Veracruz y el cuartelazo de la Ciudadela. ${ }^{23}$

Efectivamente, Carrillo vivía en la pobreza y poco después murió en la pobreza. Es la prueba que él ofrece de su honestidad en el ejer-

${ }^{20}$ Victoriano Salado Álvarez, Memorias. I. Tiempo viejo, 1946, México, Edipasa, p. 243.

${ }^{21}$ Ibid.

${ }^{22}$ El Correo del Lunes, 14 de agosto de 1882, citado por Gantús, op. cit.

${ }^{23}$ El prólogo en su versión original, mecanuscrita, se encuentra en el Archivo Histórico de la Secretaría de Relaciones Exteriores, expediente P1130463-P1130694. 
cicio periodístico. Ante el conjunto de las evidencias, alguien podrá alegar, por supuesto, que acaso fue Carrillo un hombre ineficazmente deshonesto, que no supo practicar bien la "virtud chantajista", razón por la cual terminó su vida en la pobreza. Este breve ensayo no intenta formular ese balance pues, en realidad, la fascinante complejidad del personaje está precisamente en el nodo moral de su biografía. Después de todo, y dígase lo que se diga, las Memorias de Carrillo tuvieron la enorme virtud de ser ampliamente leídas en el arranque de la Revolución y merecen ser rescatadas, con su peculiar prólogo, como parte fundamental de la historia de la literatura de combate revolucionario en el inicio del siglo XX mexicano.

Adolfo Rogaciano Carrillo nació en Sayula, Jalisco, en 1855. Su padre, Amado Carrillo, era cobrador de impuestos. Su madre se llamaba Eutimia Ramos. Ambos eran originarios de Tapalpa, Jalisco. Tuvo tres hermanos: José María, Isaac y Amado. A los 16 años, Adolfo Rogaciano se muda a Guadalajara, la capital de Jalisco, para continuar sus estudios en el Liceo de Varones. Ahí fundó el periódico La Picota, de oposición al gobierno local. Uno de los pocos que han estudiado su obra, en especial la literaria, Héctor R. Olea, dice que Carrillo era un "valiente hombre, de carácter belicoso". Poco después, cambia nuevamente su residencia y se marcha a la ciudad de México, hacia 1873, en el arranque del gobierno de Sebastián Lerdo de Tejada (1872-1876) ${ }^{24}$ La libertad de prensa, lo ha dicho y con razón Cosío Villegas, está a todo lo que da en este momento histórico de nuestro siglo XIX: existen grandes periódicos como El Monitor Republicano o El Diario del Hogar, que conviven con las mordaces hojas El Zancudo, La Mosca, La Linterna del Diablo, La Carabina de Ambrosio, La Metralla, etc. Lerdistas, antilerdistas, porfiristas, antiporfiristas: todos los grupos tienen manera de expresarse en la prensa escrita mexicana de la época, en la llamada República

${ }^{24}$ Héctor R. Olea, "Semblanza del autor", en Adolfo Rogaciano Carrillo, Memorias del Marqués de San Basilio, 1972, Puebla, Editorial Cajica. 
restaurada. Carrillo empieza a trabajar en El Republicano, de corte lerdista, en donde escribe agrias crónicas de las sesiones del Congreso. También colaborará para La Patria y hacia 1879 será director de un nuevo, y exitoso, semanario: El Correo del Lunes. Tiene entonces 24 años, y está por concluir el primer gobierno de Porfirio Díaz (1876-1880). Líos y riñas vienen y van en esta etapa de la vida de Carrillo: hacia 1883, cuatro primos y hermanos dan una paliza a Rogaciano por manchar el nombre de una dama en su periódico. Poco después, Carrillo formula agudas críticas a su colega Telésforo García, director de La Libertad. Y Telésforo reacciona violentamente. Dice Carrillo en El Tiempo del 29 de enero de 1884:

Le consta a todo el mundo el ataque alevoso de que fui víctima el martes en la tarde. Don Telésforo García me asaltó por la espalda, me derribó a tierra y sobre caído me golpeó. En esos momentos la multitud que nos rodeaba era numerosa. Llegaron los gendarmes y fuimos conducidos a la inspección. El señor García confesó los hechos [...] El Juez le impuso una multa y después hizo que el ofensor me diera una satisfacción completa, como consta en el acta respectiva.

Dos duelos de Carrillo fueron tan célebres que forman parte del 136 libro El duelo en México, publicado en $1936 .{ }^{25}$ En el primer duelo, un filoso comentario de Carrillo sobre la actriz de opereta Louise Theo llevó a Guillermo de Landa y Escandón "a retar a Carrillo por sus intemperancias para con una señora", de modo que "don José Echeverría y don Alberto Romero de Terreros pactaron con los padrinos del periodista un duelo que se verificó a un lado de la calzada de La Piedad, en el que se cambiaron dos tiros por cada parte, sin resultado". La libró Rogaciano. En la descripción del segundo combate, se subraya la idea del "ingenio" del belicoso periodista:

Un artículo publicado por Carrillo que podía perjudicar el prestigio de una dama, aunque la publicación fuera hecha en una forma muy discre-

${ }^{25}$ Ángel Escudero, El duelo en México. Recopilación de los desafios habidos en nuestra República, precedidos de la historia de la esgrima en México y de los duelos más famosos verificados en el mundo desde los juicios de Dios hasta nuestros días, 1936, México, Imprenta Mundial, prólogo de Artemio del Valle-Arizpe. 
ta, dio lugar a que Manuel Cuevas enviara al periodista sus padrinos, los señores don Rafael David y don Wenceslao Rubio. Desde luego aceptó Carrillo alegando que retirar lo escrito era dar lugar a suspicacias y a lo que según él no valía la pena formara un escándalo, prefirió un arreglo por medio de las armas eligiendo de común acuerdo la espada de combate para un encuentro que debería verificarse en la Hacienda de Los Morales. En un primer asalto, Manuel Cuevas se arrojó con verdadera decisión sobre su adversario produciéndole una seria herida en el hombro que lo imposibilitó para seguir combatiendo. ${ }^{26}$

La libró otra vez Rogaciano. Aunque salió malherido. Poco después vendrá julio de 1885: el momento clave en la biografía de Carrillo. En las últimas semanas del gobierno de Manuel González (1880-1884), Porfirio Díaz intenta que el Congreso apruebe un tratado para el reconocimiento de la deuda inglesa con el fin de endosarle el costo político al gobierno saliente. El gonzalismo se defiende con todas sus armas. Estudiantes y obreros, estimulados por la prensa gonzalista, se movilizan con el argumento de la violación de la soberanía para impedir la aprobación. Logran diferir la decisión: será el gobierno de Díaz, a partir de diciembre de 1884, quien se haga cargo del asunto. Díaz crea una comisión para discutir el tema y encuentra el modo de avanzar en un debate delicado para la relación internacional de su gobierno con las grandes potencias. Se busca una vía alterna: aprobar una ley general sobre consolidación y conversión de deuda, en donde entre líneas vaya el paquete inglés. La prensa de oposición denuncia el subterfugio y nuevamente la movilización se enciende. El Tiempo del 8 de julio de 1885 denuncia que Carrillo (de El Correo del Lunes) y una media docena de periodistas, muy destacadamente Enrique Chávarri (de El Monitor Republicano), junto con una veintena de estudiantes, han sido puestos en prisión acusados por el delito de sedición. También da cuenta de que "los números de El Correo del Lunes fueron recogidos antenoche por orden de la autoridad". El 10 de julio, es decir, dos días después, El Tiempo especula sobre la posibilidad de que se lleven a los presos a San

${ }^{26}$ Ibid. Los duelos se describen en las pp. 238-40 y 254-5. 
Juan de Ulúa, en Veracruz. Semana y media después, se suspende la publicación de El Correo del Lunes. El periódico El Tiempo del 21 de julio da cuenta de la "grande algazara en las redacciones de El Partido Liberal y de El Pacto Federal, porque se suspendió El Correo del Lunes". Afirma el editor, con ironía: "Así vamos bien, dicen ellos; "concluido El Tiempo y los demás quisquillosos calumniadores como El Correo, quedamos solos los de la subvención' ¡ ¡Viva la libertad de imprenta!” Así, periodistas y estudiantes, pasan en prisión tres meses, hasta que viene la sentencia del Juez $2^{\circ}$ de Distrito: 7 meses y 18 días de prisión para Carrillo y Chávarri y penas menores para el resto de los ofensores de la "moral pública". El asunto se lleva a la Suprema Corte y ésta, el 11 de noviembre de 1885, reduce la sanción a 4 meses y 10 días de prisión, a computarse "desde el día en que se les declaró bien presos". Pocos días después, en la segunda mitad de noviembre, Adolfo Rogaciano Carrillo es puesto en libertad.

Sin embargo, apenas deja la cárcel recibe un claro mensaje de Porfirio Díaz y su grupo. Un colaborador de El Correo del Lunes, Adolfo Paz, recibe la visita de un enviado de José Yves Limantour, hombre cercano a Díaz, quien le muestra una carta firmada con el pseudónimo que utilizaba el propio Paz en el periódico, en la que éste chantajea a Limantour con publicar "hechos vergonzosos de su amado padre". Paz niega el hecho y alega que todo lo fraguó Carrillo para perjudicarlo. Adolfo Rogaciano responde de inmediato en El Tiempo del 10 de diciembre de 1885:

Don Adolfo Paz, a quien juzgo un loco o un imbécil, me inculpa ciertos hechos totalmente absurdos o inverosímiles, pretendiendo lastimar mi reputación. Inmediatamente me presenté ante el Ministerio Público, acusando a aquel individuo de difamación y calumnia, porque lo que me imputa alevosamente no es posible de arreglarlo en otro terreno. Mi honradez y caballerosidad se sienten lastimadas y desde luego he de dejarlas ante los tribunales perfectamente depuradas. 
Pero su suerte ya está echada. Ni con la más perfecta depuración de su honradez puede evitar poner en riesgo la vida. La amenaza es bastante clara. Hay que salir del país para salvar el pellejo. Ora dice que se autoexilia, ora que fue escoltado por miembros del ejército hacia el puerto de Veracruz. Lo cierto es que Adolfo Rogaciano Carrillo se embarca en Veracruz hacia Nueva York en febrero de 1886, para no volver nunca a México.

Llega a Nueva York sin un centavo en la bolsa y tiene la fortuna de ser alojado por otro mexicano en el exilio, el ex-presidente Lerdo de Tejada, en Lenox House, y de convivir con él alrededor de nueve meses de aquel 1886. Carrillo el periodista, enemigo acérrimo de Porfirio Díaz, de pluma cáustica y demoledora, se encontrará con el enemigo por excelencia de Díaz, Sebastián Lerdo de Tejada, de filosos, hirientes y punzocortantes juicios sobre sus adversarios. Explosiva combinación de talento veracruzano y jalisciense en Nueva York. ${ }^{27}$ Uno de los pocos estudiosos de la obra de Carrillo, Leonardo Pasquel, imagina en 1959 esas largas conversaciones entre Rogaciano (a los 31 años) y Sebastián (a los 63):

Por las noches y al abrigo de la encendida chimenea, Lerdo y Carrillo charlaban tendido y sabroso, cayendo, invariablemente, en el tema que a uno y otro interesaba y que unía a ambos: su encono contra Porfirio Díaz y sus colaboradores. Fue así como Lerdo poco a poco fue aumentando el tono de los desahogos, entre copa y copa de fino coñac francés [...] De seguro pocos tuvieron las oportunidades de Adolfo Carrillo para escucharle con tanta frecuencia, refiriéndose a hechos y personas de México, ya que el ilustre veracruzano gozaba explayándose ante el joven y fogoso periodista, igualmente acérrimo enemigo del dictador. Lerdo daba salida a sus resentimientos mientras construía frases de arquitectura helénica, lapidarias, fulminantes e impecables [...] siempre dispuesto a pulverizar con la sentencia demoledora o con el estilo agudo y de corte florentino. ${ }^{28}$

${ }^{27}$ En su prólogo de 1926, Carrillo afirma haber hecho amistad también con el poeta y político cubano José Martí, y haber propiciado un encuentro entre ambos.

${ }^{28}$ Leonardo Pasquel, "Estudio preliminar", en Memorias de Sebastián Lerdo de Tejada, 1959, México, Editorial Citlaltépetl, Colección Suma Veracruzana, Serie Política. 
Pasquel llega a afirmar que "cabe pensar si no fue Lerdo de Tejada quien en cierto modo sugiriera la idea de que Carrillo escribiera las Memorias, ya que es indudable que con tanto material acumulado -desde luego de enorme importancia para un periodista-éste fácilmente hubiese concebido la forma de aprovecharlo". Pero, ¿cuál podría ser la relación entre el "material acumulado", tan periodísticamente "aprovechable", con la presunta sugerencia de Lerdo a Carrillo para que escribiera unas Memorias?

Animado por el propio Lerdo de Tejada, Adolfo Rogaciano Carrillo sale a Europa para convertirse allá en el vocero de las víctimas de la represión de la dictadura porfiriana. Pero primero va a San Francisco (y escribe para La República) y luego a La Habana (en donde escribe para El Popular). Precisamente en El Popular, en su edición del 1o. de marzo de 1887, Carrillo confiesa los móviles que lo impulsan en el arranque de una nueva etapa de su vida. Su artículo se llamó "Rusia en América":

En la campaña que como mexicano inicio contra el corrompido y absolutista gobierno de México, no me guía más espíritu que el de la lealtad patriótica. Al emprenderla tengo la conciencia de proceder como hombre honrado [... L La filosofía de Porfirio Díaz, como la de Felipe II, es tristemente impenetrable: no revela ninguna emoción cuando se divierte, ni mucho menos cuando fusila. Hay algo en él más impasible que la máscara inerte del viejo Edipo: cuando expidió por telégrafo la orden de los fusilamientos en Veracruz, no se desprendió ni una lágrima de sus pupilas felinas, y eso que tiene una facilidad maravillosa para verterlas [...] Ahora el sufragio es una quimera, en los gobiernos de los Estados ha colocado a todos sus generales y en el Congreso y en la Corte a todos sus amigos; sancionó la deuda inglesa considerada atentatoria para la autonomía nacional; triplicó los impuestos del timbre; restringió la libertad de pensamiento y [...] ahora pretende simplemente prorrogar su periodo. Urge purificar esa atmósfera viciada, apelando al único desinfectante de las descomposiciones morales: el periodismo. Por ese sistema de fumigación intelectual se evita el contagio: una gota de tinta puede hacer más que un grano de pólvora. ${ }^{29}$

${ }^{29}$ Los recortes periodísticos se encuentran en el Archivo Histórico de la Secretaría de Relaciones Exteriores, expedientes P1130297-P1130450. 
Y nuevamente en La Habana se le acusará de chantajista. Jorge Tejedor, el director del diario La Justicia, alega, en la edición de El Centinela del 13 de enero de 1888, que generosamente dio trabajo a Carrillo, debido a "la miseria que le rodeaba". Pero Carrillo "sorprendió la buena fe del director: descendió al terreno de la vida privada, de las personalidades y del chantaje". No se aclara del todo el conflicto, pero Tejedor afirma contundente que Carrillo chantajeó a un tal señor Herrera. Su principal objeto, dice Tejedor, era que "por medio del periódico [...] el Sr. Herrera le arrojara un hueso que roer, o un pequeño mendrugo con que saciar el hambre", pues Carrillo "anda a la caza de honras que mancillar, o vidas privadas que sacar a la superficie". Furioso, Carrillo responde a Tejedor en El Pueblo Soberano del 14 de enero de 1888. Niega las acusaciones y afirma: "Usted es un cobarde y un miserable, no le escupiría a la cara porque se ensuciaría mi saliva en su inmunda máscara". ${ }^{30}$

Pronto, Carrillo saldrá para España, vivirá en Madrid y escribirá para El Liberal sus críticas al régimen de Díaz. Pero no se prolongará mucho su estancia en España por la hostilidad permanente del embajador mexicano, Vicente Riva Palacio. De él dijo en las Memorias, en boca de Sebastián:

Riva Palacio es un mestizo de 60 años, un poco jorobado y patizambo [...] desbordado de ingenio, pero ingenio en forma agresiva e insana. Cuando el señor Riva Palacio quiere pelear, coge la pluma, y cuando quiere escribir, coge la espada. Riva Palacio es un hombre que ha derramado más tinta que sangre, porque estoy seguro que en su vida no ha matado ni un mosquito.

Carrillo tuvo que salir muy pronto de España para ir a Francia. En París escribió para el diario El Intransigente, pero el embajador Ramón Fernández también le hizo ahí la vida imposible. Hacia noviembre de 1888, Adolfo Rogaciano Carrillo está de regreso en Nueva York. Su tarea -la de difundir en el mundo la verdad sobre el régimen de Porfirio

${ }^{30} \mathrm{Ibid}$. 
Díaz- no ha sido exitosa. Su situación económica es crítica. Viaja a San Francisco a probar suerte. En México, ya ningún periódico admite sus artículos: todos temen enfurecer a Díaz si se le ofrecen espacios a su empeñoso detractor. Y el dictador no lo suelta: su embajador en Washington impulsa que se le detenga en territorio estadounidense por el delito de difamación. "Carrillo - nos dice Olea- fue arrestado en el mes de noviembre de 1888, acusado de difamación al gobierno de Díaz, sujeto a la indignidad de ser conducido maniatado por las calles de San Francisco". ${ }^{31}$ Carrillo será liberado muy pronto, pero con la detención recibía otro mensaje de Díaz: no se le dejará en paz ni un minuto. Poco tiempo después, en abril de 1889, muere Sebastián Lerdo de Tejada y Adolfo Rogaciano empieza, en San Francisco, a escribir las Memorias que publicará por entregas en el periódico El Mundo.

Hay algo sorprendente en el legado, como escritor, de Adolfo Rogaciano Carrillo: es más conocido por sus cuentos que por las Memorias de Sebastián Lerdo de Tejada. Efectivamente, Carrillo publicó hacia 1922 una compilación de sus Cuentos californianos. Venturosamente, la Secretaría de Cultura del Estado de Jalisco reeditó los Cuentos californianos en 1993, con un interesante prólogo de Vicente López Rojo, en el que el autor afirma que Carrillo debe ser visto como un "precursor de la literatura chicana": "Carrillo marca el deslinde entre los periodos de Transición (1848-1910) e Interacción (1910-1942), antecedentes ambos del periodo chicano que va de 1942 hasta el presente". Gran parte de los relatos de Carrillo se desarrollan en el período previo a la guerra con los Estados Unidos, y "dramatizan el conflicto cultural entre mexicanos y angloamericanos de diferentes clases sociales". Dice López Rojo:

La colección de Cuentos californianos de Adolfo Carrillo encierra una variedad de temas históricos y sociales y de registros artísticos que

${ }^{31}$ Héctor E. Olea, "Semblanza del autor", op. cit. 
versan desde lo humorístico y satírico hasta lo trágico y melodramático. Aunque no todos los relatos tienen gran valor artístico, sí merecen estudio como artefactos históricos y culturales que ayudan a contextualizar la literatura chicana de hoy. ${ }^{32}$

Más recientemente, en La Sátira chicana. Un estudio de cultura literaria, Guillermo E. Hernández pone los Cuentos californianos en el centro de su análisis del modo en que evoluciona el concepto de lo "pocho" en la literatura chicana a lo largo del siglo XIX y XX. ${ }^{33}$

Por otro lado, hacia finales del XIX, Carrillo publica otro libro de memorias, titulado Memorias del Marqués de San Basilio. Es propiamente una novela picaresca, llena de humor y -para no variar-de juicios devastadores sobre el personaje central, Jorge Carmona (Camonina en la novela), un sinaloense empeñado en mejorar su condición social que recurre a la astucia, el engaño y la estafa para lograr su objetivo. Carmona compró el título de Marqués de San Basilio y vivió un tiempo en París. El Marqués fue conservador, liberal, imperialista, se casa con una viuda rica y enviuda él para continuar su vida de lujo y excentricidad. Carrillo afirma haber publicado la obra en Barcelona (1890) y en San Francisco (1897), si bien no ha sido posible localizar dichas ediciones. Sólo dos ediciones mexicanas se conocen de este libro de Carrillo:

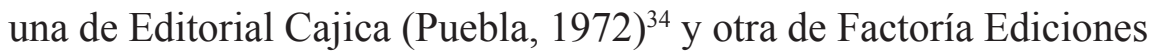
(México, 2004). ${ }^{35}$ En la edición de 2004, Bernardo Ortiz de Montellano nos llama a ver en ese "incógnito Marqués de Sinaloa", una novela de "la picaresca-fecunda en la literatura mexicana", que debe

${ }^{32}$ Adolfo Carrillo, Cuentos californianos, 1993, Guadalajara, Secretaría de Cultura de Jalisco, con un estudio introductorio de Miguel López Rojo.

${ }^{33}$ El libro se publicó en México, en 1991, bajo el sello editorial de Siglo XXI. Vale decir que una lectura actual de los cuentos y ensayos de Carrillo puede identificarlo ora clasista, ora racista, ora sexista. Hay que leerlos sin embargo tomando en cuenta su contexto histórico y cultural.

${ }^{34}$ Adolfo Rogaciano Carrillo, Memorias del Marqués de San Basilio, op. cit., con la "Semblanza del autor" de Héctor R. Olea.

${ }^{35}$ Adolfo Carrillo, Memorias del Marqués de San Basilisco, 2004, México, Factoría Ediciones, con una "Presentación" de Bernardo Ortiz de Montellano. El propio Ortiz de Montellano empieza su ensayo aclarando la peculiar diferencia en el título de ambas ediciones (Basilio en la de 1972, Basilisco en la de 2004). 
ser vista como parte de "la historia verdadera de nuestra literatura en el siglo XIX".

Todo indica, por otro lado, que las Memorias de Carrillo dejaron su impronta en el mundo periodístico. Poco tiempo antes de la muerte del dictador Victoriano Huerta, aparecieron en 1915 sus Memorias. Dice en 1975 Javier Ramos Malzárraga: "Se asegura que no son auténticas y se atribuyen a un periodista, Joaquín Piña, que conoció la psicología y la personalidad de Huerta. Sin embargo, es un libro que parece haber surgido de la mente del frustrado dictador". Cuarenta años antes, un colaborador de Huerta, Toribio Esquivel Obregón, afirmaba algo que ya nos suena familiar:

Corre por ahí un pequeño libro que se dice contiene las Memorias de Huerta: se cree que es apócrifo, y si con ello se quiere decir que Huerta no lo escribió ni dictó, creo que efectivamente no lo hizo. No puedo imaginarme a Huerta sentado media hora cada día en obra continuada y paciente, escribiendo o dictando; pero es evidente que el autor oyó mucho a Huerta y tomó directamente de él frases, opiniones y relatos, porque aquel libro es una exacta psicología de Huerta, es un documento humano, que a los que conocimos a Huerta y leemos el libro nos hace la ilusión de estar oyendo a aquel. ${ }^{36}$

Por todo lo expuesto hasta aquí, es claro que la figura de Adolfo Rogaciano Carrillo merece una revisión desde la historia y desde la literatura. Tenemos visiones sobre momentos del personaje, o sobre aspectos del personaje, pero no una aproximación completa a Carrillo. Gracias a Fernández Cué, a Puga y Acal, a Cosío Villegas, a Knapp, a Pasquel, a Gantús, a Ross, a Olea, a López Rojo, a Hernández, a Ortiz de Montellano, a los acervos del Archivo General de la Nación, a la revisión del expediente de Carrillo en el Archivo Histórico de la Canci-

${ }^{36}$ Toribio Esquivel Obregón, Mi labor en servicio de México, 1934, México, Ediciones Botas, p. 121. El texto de Ramos se puede consultar en Yo, Victoriano Huerta, 1975, México, Editorial Contenido. No he localizado la primera edición del libro de Joaquín Piña, pero hay otra, de Ediciones Vértice, titulada Memorias de Victoriano Huerta, 1957, México, reeditada en 2004 por el Senado de la República, con prólogo de Josefina Mac Gregor. Agradezco a José Emilio Pacheco esta valiosa información sobre el paralelismo entre las Memorias de Lerdo y las de Huerta, ambas de factura periodística. 
llería mexicana, así como a la consulta directa de fuentes hemerográficas, hemos podido aproximarnos al personaje para explicar al lector las vicisitudes de las Memorias y de su autor. Un periodista que entrevistó a Adolfo Rogaciano Carrillo en marzo de 1926, poco antes de morir, en la oficina del consulado en Los Ángeles, lo describe como "agrio personaje cruelmente tratado por la vida". Lo ve "considerablemente encogido". Lo pinta "enjuto", "demacrado", "marchito". "Se siente uno entonces -dice el pícaro periodista Baltazar Fernández Cué- como si estuviese en presencia de uno de esos documentos históricos que suelen hallarse en vitrinas de museos". ${ }^{37}$ Carrillo camina con dificultad al final de su vida porque diez años antes, en 1916, ha sido atropellado por un automóvil en San Francisco. Poco antes enviuda. Su prólogo es la carta que él quiere dejar para la posteridad, antes de morir, sobre su persona y su obra. Es, en ese momento, uno de los escribientes del consulado en Los Ángeles. Ahí está Rogaciano de los pies a la cabeza. Las Memorias de Sebastián Lerdo de Tejada escritas por Rogaciano y su prólogo, son -juntas- una pieza de la historia de la política, del periodismo y de la literatura de México.

${ }^{37}$ Baltazar Fernández Cué, "El autor de las Memorias de Lerdo", Excélsior, 11 de marzo de 1926. Puga y Acal escribe su crítica a Carrillo como respuesta a la entrevista concedida a Fernández Cué en Los Ángeles. 
ALONSO LUJAMBIO

\section{EDICIONES IDENTIFICADAS DEL LIBRO \\ MEMORIAS DE SEBASTIÁN LERDO DE TEJADA}

\begin{tabular}{|c|c|}
\hline Edición & Fecha de publicación \\
\hline $\begin{array}{l}\text { Lerdo de Tejada, Sebastián. Memorias inéditas de don Sebastián Lerdo } \\
\text { de Tejada. Laredo, Texas, Tipografía de "El Mundo". }\end{array}$ & 1890 \\
\hline $\begin{array}{l}\text { Lerdo de Tejada, Sebastián. Memorias inéditas de don Sebastián Lerdo } \\
\text { de Tejada. Brownsville, Texas, Tipografía de "El Porvenir". }\end{array}$ & 1895 \\
\hline $\begin{array}{l}\text { Lerdo de Tejada, Sebastián. Memorias inéditas de don Sebastián Lerdo } \\
\text { de Tejada. Brownsville, Texas, Tipografía de "El Porvenir". }\end{array}$ & 1898 \\
\hline $\begin{array}{l}\text { Lerdo de Tejada, Sebastián. Memorias inéditas de don Sebastián Lerdo } \\
\text { de Tejada. San Diego, California. Tipografía de "La Libertad". }\end{array}$ & 1905 \\
\hline $\begin{array}{l}\text { Lerdo de Tejada, Sebastián. Memorias de D. Sebastián Lerdo de Tejada. } \\
\text { México, Imprenta Popular. }\end{array}$ & $\mathrm{s} / \mathrm{f}$ \\
\hline $\begin{array}{l}\text { Lerdo de Tejada, Sebastián. Memorias inéditas de don Sebastián Lerdo de } \\
\text { Tejada. Brownsville, Texas, Tipografia de "El Porvenir". Novísima edición. }\end{array}$ & $1910-1912$ \\
\hline $\begin{array}{l}\text { Lerdo de Tejada, Sebastián. Memorias del presidente de la República } \\
\text { Mexicana, Lic. Sebastián Lerdo de Tejada, juzgando a los hombres de } \\
\text { Tuxtepec. México, editorial de El Partido Liberal Rojo. }\end{array}$ & 1911 \\
\hline $\begin{array}{l}\text { Lerdo de Tejada, Sebastián. Memorias inéditas de don Sebastián Lerdo } \\
\text { de Tejada. San Antonio, Texas. Imprenta de "El Monitor Democrático" }\end{array}$ & 1911 \\
\hline $\begin{array}{l}\text { Lerdo de Tejada, Sebastián. Memorias inéditas de don Sebastián Lerdo } \\
\text { de Tejada. México, Tipografía Mexicana. }\end{array}$ & 1911 \\
\hline $\begin{array}{l}\text { Lerdo de Tejada, Sebastián. Memorias inéditas de don Sebastián Lerdo } \\
\text { de Tejada. Puebla, José Ernesto Limón, editor. }\end{array}$ & 1911 \\
\hline $\begin{array}{l}\text { Lerdo de Tejada, Sebastián. Memorias inéditas de don Sebastián Lerdo de } \\
\text { Tejada. Guadalajara, Jalisco, Tipografía de "La Gaceta de Guadalajara". }\end{array}$ & 1911 \\
\hline $\begin{array}{l}\text { Lerdo de Tejada, Sebastián. Memorias de Sebastián Lerdo de Tejada. } \\
\text { Prólogo de Leonardo Pasquel. México, Editorial Citlaltépetl. }\end{array}$ & 1959 \\
\hline $\begin{array}{l}\text { Lerdo de Tejada, Sebastián. Memorias inéditas de don Sebastián Lerdo de } \\
\text { Tejada. Prólogo de José Bulnes. México, Consejo Editorial del Gobierno } \\
\text { del estado de Tabasco. }\end{array}$ & 1980 \\
\hline
\end{tabular}

Estudios 99, vol. X, invierno 2011 